\title{
Bone marrow stromal cells mediate androgenic suppression of B lymphocyte development
}

\author{
Nancy J. Olsen, ${ }^{1}$ Xiujing Gu, ${ }^{1}$ and William J. Kovacs ${ }^{2,3}$ \\ ${ }^{1}$ Division of Rheumatology and Immunology, and \\ ${ }^{2}$ Division of Diabetes, Endocrinology and Metabolism, Department of Medicine, Vanderbilt University, \\ Nashville, Tennessee, USA \\ ${ }^{3}$ Department of Veterans Affairs Medical Center, Nashville, Tennessee, USA \\ Address correspondence to: Nancy J. Olsen, T-3219 Medical Center North, \\ Vanderbilt University, Nashville, Tennessee 37232, USA. \\ Phone: (615) 322-4746; Fax: (615) 322-6248; E-mail: nancy.olsen@mcmail.vanderbilt.edu.
}

Received for publication May 2, 2001, and accepted in revised form October 2, 2001.

Castration of normal male mice induces expansion of the bone marrow B cell population, an effect that can be reversed by androgen replacement. We employed in vitro cultures and two in vivo models to investigate whether androgens exert these effects directly on marrow lymphoid precursors or whether actions on marrow stromal elements are required. Immature B cells from normal mouse bone marrow were not responsive to the suppressive effect of androgens unless they were cocultured with marrow stromal cells or with supernatants from androgen-treated stromal cells, suggesting that the androgen effects are exerted through marrow stromal elements by production of a diffusible mediator. Further experiments revealed that bone marrow stromal cells produced TGF- $\beta$ in response to dihydrotestosterone (DHT), and neutralization of TGF- $\beta$ in the DHT-treated stromal cells reversed the suppressive effects. The stromal cell requirement for androgen-mediated effects was confirmed in vivo by experiments using chimeric animals created by bone marrow transplantation in which androgen receptor expression was restricted to either the stromal or lymphoid cells of the bone marrow. Androgens only affected B cell development in chimeric mice with androgen-sensitive stromal cells. These experiments suggest that effects of androgens on developing B cells are mediated through androgen receptors in bone marrow stromal cells. TGF- $\beta$ is a candidate mediator for these hormonal effects.

J. Clin. Invest. 108:1697-1704 (2001). DOI:10.1172/JCI200113183.

\section{Introduction}

Several lines of evidence support the hypothesis that gonadal steroids exert effects on the development of $\mathrm{B}$ cells in bone marrow. In normal female rats and mice, ovariectomy results in increased numbers of bone marrow B cells (1-3). Pregnancy or estrogen treatment in mice is associated with significant decreases in numbers of B cell bone marrow precursors $(4,5)$. Furthermore, when estrogens are added to in vivo or in vitro systems, suppressive effects on B cell development are observed $(3,6)$. Bone marrow stromal cells express estrogen receptors and are thought to mediate these negative regulatory effects of estrogens on an early pre-B cell target (5, 7). The stromal cell products responsible for these effects of estrogens have not been identified. Studies in ER $\alpha$ knockout mice indicate that this form of the estrogen receptor, expressed in either the lymphoid or stromal cell compartments, is necessary for development of normal numbers of bone marrow B cells (8).

Androgens also exert effects on B cell development in bone marrow. Castration of normal male mice results in enlargement of the $B$ cell population in the bone marrow and the spleen (9-11). Androgen replacement with either testosterone or dihydrotestosterone (DHT) reverses this effect (12). Androgen-resistant testicular feminization (Tfm) mice also show expansion of B cell populations in spleen and bone marrow $(7,13)$. The target cells of androgen action in the bone marrow are not known, although pre-B cells, unseparated mouse bone marrow cells, and bone marrow stromal cell lines all have been found to express androgen receptors, suggesting that either lymphoid or stromal elements in bone marrow are potential targets of androgen action (12).

We describe experiments designed to investigate the cellular targets of androgen action on developing bone marrow B cells. Androgen effects and stromal-lymphoid interactions were studied both in vitro and in vivo. The data indicate that androgenic hormones can modulate $\mathrm{B}$ cell development by regulating expression of marrow stromal cell products such as TGF- $\beta$.

\section{Methods}

Bone marrow and stromal cells. Animal care and all procedures were approved by the Vanderbilt University Animal Care Committee. C57BL/6 mice (Harlan, Indianapolis, Indiana, USA) were used as the marrow source for in vitro experiments. Animals were castrated at 3-4 weeks of age to avoid carry-over of endogenous androgens into the cultures. Studies were carried out 10 days after castration, at which time serum testosterone levels are not detectable (14). Bone marrow cells were obtained from the tibias and femurs of each animal by flushing 
the marrow cavity with RPMI 1640 medium (Life Technologies Inc., Grand Island, New York, USA) using a syringe equipped with a 25 -gauge needle. Cell suspensions were prepared by homogenizing the extruded marrow between the frosted ends of sterile microscope slides. The M2-10B4 bone marrow stromal cell line was obtained from the American Type Culture Collection (Manassas, Virginia, USA). These fibroblastoid bone marrow stromal cells express androgen receptors (12) and support in vitro differentiation of immature $B$ cells (15). Cells were maintained in adherent culture in RPMI 1640 medium (Life Technologies Inc.) supplemented with 10\% FCS (Life Technologies Inc.) and were passaged by treatment with trypsin/EDTA (Life Technologies Inc.). Stromal cells from testicular feminization mice were derived from marrow samples that were cultured in RPMI 1640 medium with $10 \%$ FCS. Adherent cells were passaged by trypsinization and studies were performed after three to five passages in vitro.

Cocultures of M2-10B4 cells and bone marrow cells. In some experiments, bone marrow cells $\left(7.5 \times 10^{6}\right.$ to $\left.10 \times 10^{6}\right)$ were cultured in direct contact with M2-10B4 cells $\left(3 \times 10^{5}\right)$ in 4 -well dishes (Corning Life Sciences. Corning, New York, USA) in $10 \mathrm{ml}$ of RPMI/10\% charcoal-stripped FCS (CSFCS; Hyclone Laboratories, Logan, Utah, USA). These cultures contained IL-7 $(1 \mathrm{ng} / \mathrm{ml})$, which was resupplied midway through the 10-day culture period. DHT $(1 \mu \mathrm{M})$ or the ethanol vehicle was added to selected cultures. Nonadherent lymphoid cells were washed from the adherent monolayer by vigorous pipetting with cold PBS and prepared for flow cytometric analysis.

Soft agar cultures. B cell cloning in semisolid agar was performed using the method described by Kincade and colleagues $(16,17)$. Under these conditions, IL-7 induces dose-dependent proliferation of immature B cell precursors (18). Bone marrow cells were suspended in $0.3 \%$ agarose (Sigma Chemical Co., St. Louis, Missouri, USA) and McCoy's medium (Life Technologies Inc.), supplemented with $\mathrm{NaHCO}_{3}, 2 \mathrm{mM}$ L-glutamine, $16 \mu \mathrm{g} / \mathrm{ml}$ L-asparagine, $8 \mu \mathrm{g} / \mathrm{ml} \mathrm{L}$-serine, $1 \mathrm{mM}$ sodium pyruvate, $0.8 \%$ MEM essential amino acids mixture $(50 \times$; Life Technologies Inc.), $0.4 \%$ MEM nonessential amino acids mixture (100×; Life Technologies Inc.), $0.6 \%$ sodium bicarbonate solution (7.5\%), $5 \times 10^{-5} \mathrm{M} 2$-mercaptoethanol, and $15 \%$ CSFCS. The warmed agarose was added to the cells and medium immediately before dispensing into 48well culture dishes (Corning Life Sciences, Acton, Massachusetts, USA). Each well contained $2 \times 10^{4}$ bone marrow cells in a total volume of $0.20 \mathrm{ml}$ of the agarose/medium.

Recombinant murine IL-7 (Endogen Inc., Woburn, Massachusetts, USA) was used in concentrations of $0.1-50 \mathrm{ng} / \mathrm{ml}$ for the dose-response curve and at 1 $\mathrm{ng} / \mathrm{ml}$ for subsequent experiments. Dexamethasone (DEX) and DHT (Sigma Chemical Co.) were added to soft agar cultures at various concentrations $\left(10^{-6}\right.$ to $10^{-10} \mathrm{M}$ ), as indicated in the individual experiments. Control cultures without added hormones or IL-7 produced $1.3 \pm 0.5$ colonies per $10^{5}$ input cells.
Some soft agar cultures were done in the presence of an underlying monolayer of M2-10B4 stromal cells. For cultures with the stromal layer, $2.5 \times 10^{3} \mathrm{M} 2-10 \mathrm{~B} 4$ cells in RPMI $/ 10 \%$ FCS were added to the wells and allowed to adhere overnight at $37^{\circ} \mathrm{C}$ in an atmosphere of $5 \%$ $\mathrm{CO}_{2}$. The adherent cell layer was washed with RPMI/10\% CSFCS and bone marrow cells suspended in agarose were added, so that the B cells were not in direct contact with the stromal cell layer. M2-10B4 stromal cells are known to produce B cell growth factors (19), and preliminary experiments showed no additive effect of exogenous IL-7 on B cell colony formation in the presence of 10B4 cells (data not shown). Therefore, these cultures were done without added IL-7. Cultures were incubated for $6-10$ days at $37^{\circ} \mathrm{C}$ in an atmosphere of $5 \% \mathrm{CO}_{2}$, and colony formation was quantitated using an inverted microscope. A colony was defined as a cluster of at least 20 cells. Results were expressed as the number of colonies per $10^{5}$ bone marrow cells that were originally added to the cultures. In some experiments, neutralization of TGF- $\beta$ was achieved by addition of a pan-specific anti-TGF- $\beta$ antibody (R\&D Systems Inc., Minneapolis, Minnesota, USA) at a final concentration of $33 \mu \mathrm{g} / \mathrm{ml}$. The neutralization dose 50 of this antibody for porcine TGF- $\beta_{1}$ is estimated by the manufacturer to be $5 \mu \mathrm{g} / \mathrm{ml}$.

Stromal cell supernatants. In some experiments, supernatants from the M2-10B4 stromal cell line or from Tfm stromal cell cultures were incorporated into the agarose at final concentrations of 5-20\%. Supernatants were prepared in 48-well plates (Corning Life Sciences), with $2.5 \times 10^{3} \mathrm{M} 2-10 \mathrm{~B} 4$ cells seeded per well in $1 \mathrm{ml}$ RPMI with 10\% FCS. Cells were allowed to adhere overnight, and monolayers were washed with plain RPMI. Each well then received RPMI/10\% CSFCS $(1 \mathrm{ml})$ supplemented with DHT at $1 \mu \mathrm{M}$ or a corresponding concentration of the ethanol vehicle alone. Supernatants were harvested after an incubation period of 1 week and stored in aliquots at $-70^{\circ} \mathrm{C}$ until use. These supernatants contain approximately $0.5 \mathrm{ng} / \mathrm{ml}$ of bioactive IL-7, as measured in the colony formation assay, and therefore cultures containing these supernatants were not supplemented with exogenous IL-7.

TGF- $\beta$ RNA expression. M2-10B4 cells were cultured in $10 \%$ CSFCS for 3 days. Cultures contained either DHT (1 $\mu \mathrm{M})$ or the ethanol vehicle alone. Total RNA was prepared from the harvested cells using a commercial kit (RNeasy; QIAGEN Inc., Valencia, California, USA) and used as a template for RT-PCR with primers specific for murine TGF- $\beta$ (CLONTECH Laboratories Inc., Palo Alto, California, USA). $\beta$-actin messenger RNA was amplified as a control. The gels were transferred to a filter and hybridized with a radiolabeled TGF- $\beta$ cDNA probe (20) or with a $\beta$-actin probe prepared by PCR amplification. Blots were washed and exposed to Kodak XAR film(Eastman Kodak Co., Rochester, New York, USA).

TGF- $\beta$ immunoassay. Measurement of TGF- $\beta$ in culture supernatants was done using the Quantikine kit $(R \& D$ Systems Inc.). This assay is specific for the TGF- $\beta_{1}$ iso- 
a

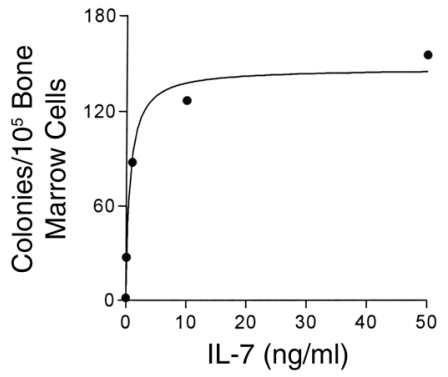

b

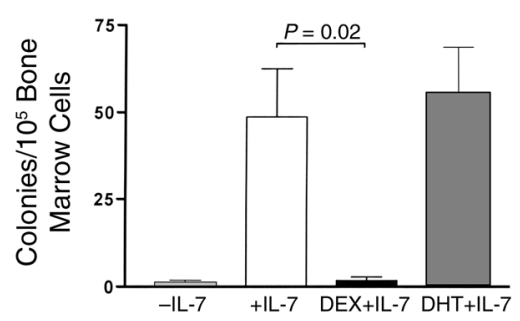

\section{Figure 1}

(a) Dose-response curve for IL-7-induced colony formation by bone marrow cells in soft agar. Colonies were counted after 7 days of incubation, and results are expressed as the mean values from three separate experiments. (b) Androgens do not suppress IL-7-stimulated B cell colony formation by isolated marrow cells. Bone marrow cells were cultured in soft agar under control conditions (-IL-7) or with added IL-7. DEX $\left(10^{-6} \mathrm{M}\right)$ or DHT $\left(10^{-6} \mathrm{M}\right)$ were added to some cultures with IL-7. Data shown are results from four separate mice and represent mean + SEM.

form. Supernatants were acid-activated with $\mathrm{HCl}$, and neutralized prior to assay, according to the manufacturer's directions. Supernatants tested without acid activation did not contain significant amounts of immunoreactive TGF- $\beta$. A standard curve was utilized to calculate concentrations.

In vivo mouse models of androgen blockade or androgen resistance. Androgen receptor blockade was carried out in intact male C57BL/6 mice by treatment with flutamide, a nonsteroidal agent with specific and purely antagonistic action at the level of the androgen receptor (AR) (21). Animals were treated with subcutaneous flutamide pellets (10 mg or $15 \mathrm{mg}$; Innovative Research of America, Sarasota, Florida, USA) and sacrificed at the end of the 21-day release period.

Chimeric mice with AR expression in marrow restricted to either lymphoid cells or marrow stromal cells were prepared using C57BL/6 mice that were congenic for the $T$ cell surface marker Thy 1.1 and testicular feminization mice (The Jackson Laboratory, Bar Harbor, Maine, USA) as described previously (22). In brief, unseparated bone marrow cells $\left(0.5 \times 10^{6}\right)$ from donor mice were transferred intravenously into lethally irradiated (9 Gy) recipients of the opposite strain. Serum testosterone levels in irradiated recipients remained in the normal range (22). The C57 congenics express the Thy 1.1 marker on all thymus-derived (T) lymphocytes; Tfm mice express the Thy 1.2 allele. This Thy 1 marker discordance permits assessment of donor cell survival in the irradiated host; $85 \% \pm 5 \%$ of thymocytes from chimeric animals were of the donor phenotype. Animals were studied at 60 or more days after transplantation. In some experiments, recipients were castrated 60 days after transplantation. Androgen replacement was achieved in some castrated animals using subcutaneous pellets of DHT ( $0.5 \mathrm{mg}$; Innovative Research of America), and these animals were sacrificed at the completion of the 21-day release period. In previous studies we have shown that this dose of DHT reverses effects of castration on thymus size, returning it to normal (22), suggesting that physiologic levels of hormone replacement are achieved. Bone marrow cells harvested from the transplanted mice were prepared for flow cytometry in FACS buffer (PBS with $2 \%$ BSA and $0.1 \% \mathrm{NaN}_{3}$ ), and $1 \times 10^{6}$ cells were incubated with conjugated monoclonal antibodies directed against the pan-B cell surface marker B220 (Pharmingen, San Diego, California, USA) and surface IgM (Sigma Chemical Co.) at $4^{\circ} \mathrm{C}$ for 30 minutes, washed, and fixed with $1 \%$ paraformaldehyde (Electron Microscopy Sciences, Fort Washington, Pennsylvania, USA). Two-color analysis was performed on a FACStar Plus (Becton Dickinson Immunocytometry Systems, San Jose California, USA).

Statistics. Data are presented as the mean and SEM. Comparisons between groups were done using Student's $t$ test. For the in vitro assays, in which samples from one animal were exposed to different treatments, a paired $t$ test was used, comparing each hormone-treated sample to the corresponding control. $P$ values less than 0.05 are considered significant.

\section{Results}

Androgens do not directly affect the colony-forming response of bone marrow $B$ cell precursors to IL-7 in vitro. Studies of B cell colony formation by marrow cells in the presence of exogenous IL-7 revealed that half-maximal response was reached at approximately $1 \mathrm{ng} / \mathrm{ml}$ (Figure 1a). This concentration of added IL-7

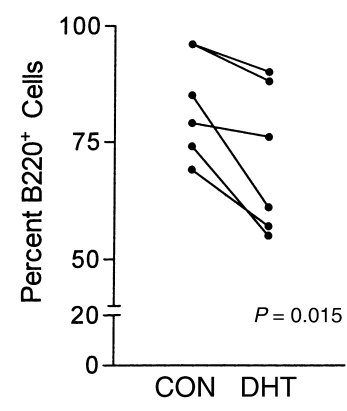

\section{Figure 2}

$B$ cell yield is diminished by DHT when marrow cells are cultured directly on monolayers of M2-10B4 marrow stromal cells. Cultures were done without or with DHT. Cells were harvested and B220+ cells quantitated by flow cytometry. Individual experiments are shown $(n=6)$. The difference between numbers of B220 cells in DHT and control cultures was statistically significant $(P=0.015$ by paired $t$ test). 


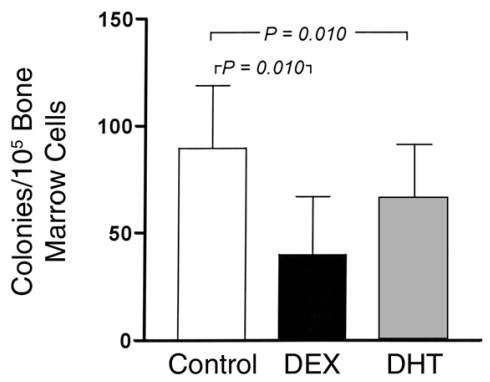

Figure 3

Androgens suppress B cell colony formation in vitro when marrow cells are cocultured in agar with M2-10B4 marrow stromal cells. Bone marrow cells were cultured over $\mathrm{M} 2-10 \mathrm{~B} 4$ monolayers without added hormone (Control) or with DEX or DHT $\left(10^{-6} \mathrm{M}\right)$. Data represent mean values + SEM. Each group includes seven to ten mice. $P$ values are calculated by paired $t$ test.

was used in experiments to evaluate any directly suppressive effects of androgens on marrow $\mathrm{B}$ cell differentiation. DHT at concentrations from $1 \mathrm{nM}$ (data not shown) to $1 \mu \mathrm{M}$ (Figure $1 \mathrm{~b}$ ) had no effect, while DEX at $1 \mu \mathrm{M}$ nearly completely prevented B cell colony formation (Figure $1 \mathrm{~b}$ ); concentrations as low as $1 \mathrm{nM}$ also prevented colony formation (data not shown). These direct effects of DEX on B cell colony formation, which are similar those reported previously using hydrocortisone (6), are thought to be the result of glucocorticoidmediated apoptotic death of B cell precursors (23). DHT does not appear to have this type of direct effect on immature B cells.

Androgens were found to exert indirect effects through the marrow stromal cells that support B cell development. When bone marrow cells were cocultured directly on a stromal cell support layer of M2-10B4 cells, suppressive effects of DHT $(1 \mu \mathrm{M})$ were observed (Figure 2). In each of six experiments, the relative number of B220 lymphocytes in the harvested cell population was lower in the cultures with DHT than in corresponding control cultures containing the vehicle alone $(P=0.015)$.

Direct cell-cell contact between stromal cells and B cell precursors was not required for the androgenic effects. When bone marrow cells were plated in soft agar over a monolayer of M2-10B4 cells, both DEX and DHT treatment resulted in diminution of the number of $\mathrm{B}$ cell colonies (Figure 3 ). In cultures with $10^{-6} \mathrm{M}$ DHT $(n=9), 66 \pm 25$ colonies were formed compared with a corresponding control of $90 \pm 29$ colonies $(P=0.010)$. Cultures with $10^{-7} \mathrm{M} \mathrm{DHT}(n=4)$ also produced significantly fewer colonies $(20.5 \% \pm 5.2 \%$ decrease; $P=0.010)$. With $10^{-8} \mathrm{M}$ DHT $(n=4)$, the decrease was $13 \%$, which was not statistically significant $(P=0.08)$. These findings suggest a role for M2-10B4-derived diffusible factors in mediating the negative effects of DHT on developing B cells. The negative effect of DEX in these cocultures was less profound than that which was observed in cultures without M2-10B4 cells (Figure 1b), suggesting that factors other than IL-7 that are secret- ed by the M2-10B4 stromal cells may rescue some B cell precursors from glucocorticoid-mediated apoptosis.

The presence of stromal cells was not required for androgens to modify B cell colony formation. Culture supernatants from androgen-treated M2-10B4 cells showed reduced ability to support B cell colony formation in each experiment performed (Figure 4). Medium from control and DHT-treated M2-10B4 cells was used to prepare soft agar cultures without added IL-7. Control 10B4 supernatants, used at final concentrations of $10 \%$ or $20 \%$, supported B cell colony formation (supplementation with $5 \%$ of supernatant was insufficient to produce colonies). In eight independent experiments, the number of colonies formed was variable, but cultures with supernatants from DHTtreated stromal cells (final concentration 10\%) produced fewer colonies than cultures with control supernatants. Differences between control and DHT cultures were modest in some instances, but the overall comparison between the treatments was significant $(P=0.0006$; Figure 4). In these paired experiments, supernatants from androgen-treated stromal cells supported, on average, the formation of $40.5 \% \pm 6.4 \%$ fewer colonies than supernatants from untreated cells. In comparable paired cultures, the addition of $20 \%$ concentrations of DHT-treated cell supernatants decreased B cell colony formation by an average of $28 \% \pm 5.3 \%$ from the corresponding control $(P=0.0093$; data not shown). The negative effects of DHT-conditioned supernatants on B cell colony formation could be due to either decreased production of a stimulatory factor or increased production of a suppressive factor. These two possibilities were evaluated in mixing experiments using DHT and control supernatants. Experiments testing supernatant concentrations of $10 \%$ and $20 \%$ showed suppressive activity in the DHT supernatants (mean $47 \%$ decrease vs. control), which persisted when mixed 1:1 with control supernatant (mean $50 \%$ decrease; $P=0.5$; paired $t$ test), suggesting the presence of a suppressive factor.

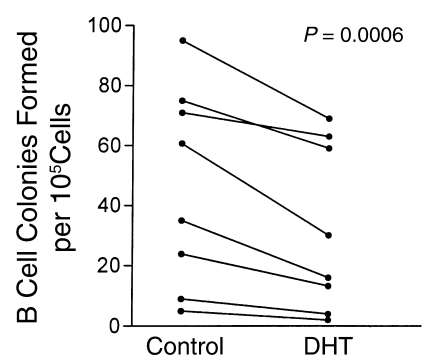

\section{Figure 4}

Conditioned medium from 10B4 murine marrow stromal cells supports $B$ cell colony formation, and this effect is diminished when the stromal cells are treated with DHT. B cell colony formation by normal murine bone marrow cells was assessed in soft agar using supernatants from control or DHT-treated 10B4 cells at a final concentration of $10 \%$. No exogenous IL-7 was added to the cultures. Results from eight separate experiments are shown. Control and DHT cultures were compared using a paired $t$ test. 


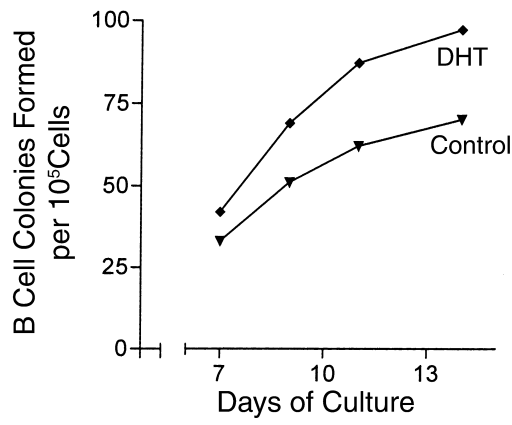

Figure 5

Supernatants generated from bone marrow stromal cells of $T f m / Y$ mice support B cell colony formation. Treatment of these stromal cells with DHT does not result in a reduced number of colonies. Results from a single experiment are shown.

To test the hypothesis that expression of AR on stromal cells was required to mediate effects of DHT, bone marrow stromal cells from a Tfm/Y mouse were grown in vitro and used to generate control and DHT-conditioned supernatants. These supernatants were incorporated into agar cultures at a final concentration of $10 \%$ and effects on colony formation by normal C57BL/ 6 bone marrow cells were examined every 2-3 days from day 7 through day 14 of culture. DHT-conditioned supernatants from these cells did not show suppression of colony numbers below those measured in control cultures at any time point (Figure 5). These findings are consistent with a requirement for AR expression by stromal cells to mediate effects of DHT on developing B lymphocytes.

The cytokine TGF- $\beta$ was investigated as a potential mediator of the inhibitory effects of DHT on marrow stromal cell support of B cell colony formation. Treatment of M2-10B4 cells with DHT resulted in induction of TGF- $\beta_{1}$ RNA (Figure $6 a$ ), with an increase relative to $\beta$-actin of 5.5-fold and 2.2-fold in two separate experiments. Upregulation of immunoreactive TGF- $\beta$ was also observed. In a series of five cultures of M2-10B4 stromal cells, the mean level of activated TGF- $\beta$ was $197 \pm 91 \mathrm{pg} / \mathrm{ml}$ in control cultures and $621 \pm 113$ $\mathrm{pg} / \mathrm{ml}$ in cultures with DHT $(P=0.018$; Figure $6 \mathrm{~b})$. Effects of neutralization of TGF- $\beta$ activity on B cell colony formation were examined in soft agar cultures of bone marrow cells over a monolayer of M2-10B4 stromal cells. In five separate experiments, the inhibitory effect of DHT on B cell colony formation was reversed by the addition of anti-TGF- $\beta(P=0.026$; Figure $6 c$ ). Addition of anti-TGF- $\beta$ alone had no significant effect on colony formation.

In vitro experiments suggest that androgens exert suppressive effects on B cell development and that these suppressive effects are exerted at the level of the marrow stromal cell. In vivo experiments with the antiandrogen flutamide support the dependence of these effects on androgen receptor signaling. Flutamide was administered to normal intact C57BL/6 male mice to inhibit androgen action in vivo and the effects on bone marrow cell populations were assessed. Both doses of flutamide (10 $\mathrm{mg}$ and $15 \mathrm{mg}$ ) were associated with expansion of the total B cell $\left(\mathrm{B} 220^{+}\right)$pool, as well as the $\mathrm{B}^{220^{+}} \mathrm{IgM}^{+}$subset of marrow B cells (Figure 7). To assess whether the requirement for androgen action at the stromal cell could also be demonstrated in vivo, bone marrow transplantation was used to create chimeric animals with AR expression restricted to either the marrow stromal cells or the marrow lymphoid compartment. Transplantation of $\mathrm{AR}^{-} \mathrm{Tfm}$ bone marrow cells into $\mathrm{AR}^{+} \mathrm{C} 57$ irradiated hosts resulted in a relative expansion in numbers of B220 cells in bone marrow $(36.5 \% \pm 5.9 \%)$ compared with normal C57BL $/ 6$ males $(18.0 \% \pm 3.0 \% ; P=0.011$; not shown). These expanded populations of cells in the $\mathrm{Tfm} \rightarrow \mathrm{C} 57$ chimeras may be due to the larger numbers of B cells in the Tfm transplant inoculum (7). Castration of these chimeras did not have a significant effect on the B cell population ( $30.6 \% \pm 3.7 \%)$, but androgen replacement with DHT resulted in an approximately a

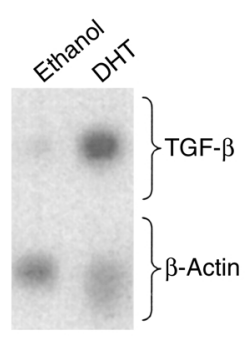

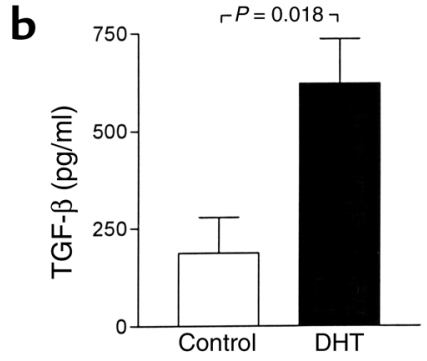

C

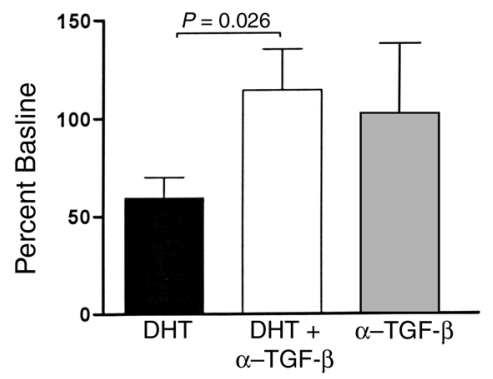

\section{Figure 6}

(a) Treatment of M2-10B4 bone marrow stromal cells with DHT results in upregulation of TGF- $\beta$ RNA levels. Adherent monolayers were treated with DHT ( $1 \mu \mathrm{M})$ or ethanol vehicle for 3 days. Total RNA was extracted, amplified by RT-PCR, and hybridized with probes for TGF- $\beta_{1}$ and $\beta$-actin. Similar results were obtained in two separate experiments, and results from one of these are shown. (b) Treatment of M2-10B4 bone marrow stromal cells with DHT results in upregulation of immunoassayable TGF- $\beta$. Adherent monolayers were treated with DHT $(1 \mu \mathrm{M})$ or ethanol vehicle for 3 days. Results shown are means \pm SEM for six experiments. (c) Neutralization of TGF- $\beta$ in vitro reverses $B$ cell suppression by DHT. Cultures in soft agar contained bone marrow cells over a 10B4 stromal cell monolayer, with and without addition of anti-TGF- $\beta(33 \mathrm{mg} / \mathrm{ml})$. Colonies produced in cultures treated with DHT and anti-TGF- $\beta$ are expressed as a percent of the corresponding control cultures containing the ethanol vehicle alone. Mean and SEM values from five separate experiments are shown. Addition of anti-TGF- $\beta$ antibody alone resulted in a mean value which was $99 \%$ of the control $(P=0.9)$. 

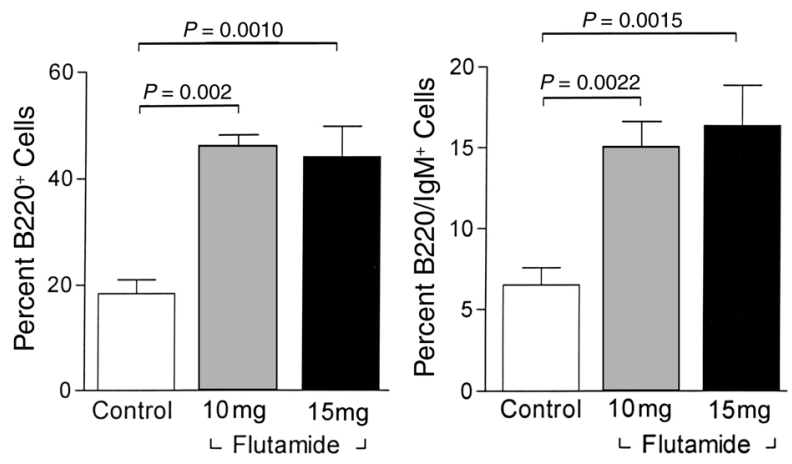

\section{Figure 7}

Bone marrow cell populations in C57 male mice treated with flutamide (10 or $15 \mathrm{mg}$ ) administered as a 21-day-release subcutaneous pellet. Results are compared with intact age-matched male control animals. Relative numbers of total $\mathrm{B} 220^{+}$cells (left) are increased in antiandrogen-treated animals, as are the cells in the more mature $\mathrm{B}^{2} 20^{+} \mathrm{IgM}^{+}$ subset (right). Values represent means \pm SEM; each flutamide group includes three mice and the control group includes nine mice.

$50 \%$ reduction in $\mathrm{B} 220$ cells, to $15.3 \% \pm 3.3 \%$ of bone marrow cells (Figure 8, left two bars). This change was largely accounted for by a reduction in the subpopulation of immature $B$ cells that do not express surface IgM, which represented $15.14 \% \pm 6.8 \%$ of bone marrow cells in castrated chimeras but only $5.0 \% \pm 1.6 \%$ of cells in marrows from DHT-treated mice $(P=0.0032)$. In contrast, when C57 bone marrow cells were transplanted into a Tfm/Y AR- recipient (Figure 8, right two bars), androgen treatment had no effect on relative numbers of bone marrow B220 cells $(31.04 \% \pm 3.0 \%$ vs. $27.76 \% \pm 6.3 \% ; P=0.63)$. These results indicate that $\mathrm{AR}^{+}$marrow stromal cells are required for androgens to exert negative effects on $\mathrm{B}$ lymphopoiesis.

\section{Discussion}

B lymphocyte development is an orderly process that takes place in bone marrow under the control of mesenchyme-derived stromal cells and cytokines or other small-molecular weight mediators produced by stromal cells and immature lymphocytes $(19,24)$. A variety of hormones have been shown to be capable of altering $B$ lymphopoiesis. Most of the effects of these hormones target the early pre-B cell stage of development. Some, such as growth hormone, IGF-I, and thyroxine, exert positive effects on B cell development (25-28). Others, including estrogens and androgens, induce negative, or downregulatory, effects $(6,12)$. Peripheral B cell expansion in the castrated male is largely due to new emigrants from the bone marrow and not to expansion of a mature population (11). This observation is consistent with the restriction of AR expression to the marrow compartment whereas mature cells in spleen, lymph node, and peripheral blood are negative for AR expression (29-31). The present studies suggest that full expression of androgen action on B lymphopoiesis requires stromal cell expression of AR and stromal cellderived mediators, including TGF- $\beta$. The amount of
TGF- $\beta$ produced by stromal cells in response to DHT is similar to that which has been shown in other systems to be capable of inhibiting greater than $60 \%$ of colony formation by lymphoid progenitor cells (32).

Of the various hormones that have known effects on $B$ cells, the actions of estrogens have been the most well characterized. Treatment of mice in vivo with estrogens results in reduced $B$ cell numbers, which are in large part due to effects on immature, cytoplasmic $\mu^{+}$pre-B cells (5). Addition of estrogen in vitro to immature $B$ cells in the absence of stromal cells has no effect on colony formation in soft agar (6). Likewise, when stromal cells are added to the cultures of bone marrow cells, estrogen inhibits B cell responsiveness to IL-7. Direct contact between the stromal cells and the lymphocytes is not required for estrogen to exert these effects, suggesting that estrogens modulate B lymphopoiesis through production of a diffusible stromal cell product (6).

The present studies indicate that androgens act through a stromal-dependent mechanism similar to estrogens, and identify TGF- $\beta$ as at least one potential stromal cell product that mediates actions of this hormone. There are many striking parallels between the effects of androgens and TGF- $\beta$ on B cell development. In previous studies, we have shown that androgens upregulate expression of TGF- $\beta$ in the thymus (20), and the present findings suggest that androgens also induce TGF- $\beta$ in the bone marrow compartment. The role of TGF- $\beta$ as a negative regulator of bone marrow B cell development has been well described $(18,33)$, and receptors for TGF- $\beta$ are expressed in bone marrow stromal cells (34). Immature B cells are very sensitive to effects of TGF- $\beta$ (35), and other studies suggest that androgen sensitivity is also directed at these immature cells (11). Mechanisms by which TGF- $\beta$ alters B cell development may include downregulation or blockade of stromal cell-

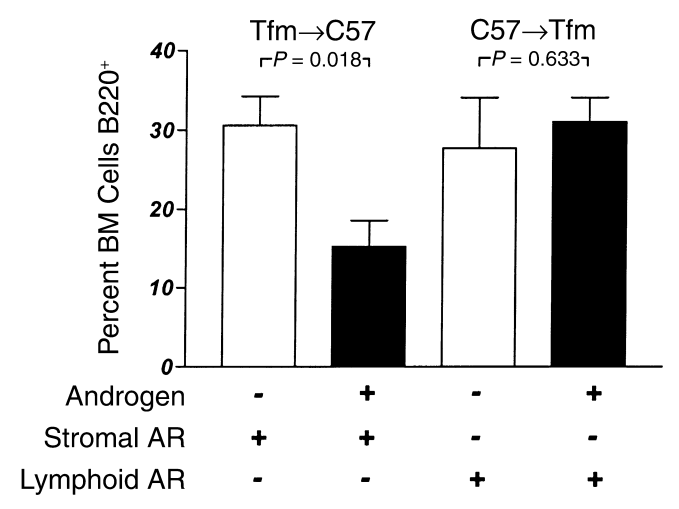

\section{Figure 8}

Bone marrow B lymphocyte populations in chimeric mice in an androgen-deficient state (open bars) and after androgen administration (filled bars). Tfm $\rightarrow$ C57 animals (left side) have AR expressed in marrow stroma but not in lymphoid cells; C57 $\rightarrow$ Tfm animals (right side) have AR expressed in lymphoid cells but not in stroma. Exogenous androgens suppress $B$ cell populations only in the presence of $\mathrm{AR}^{+}$stroma in vivo. 
derived IL-7 (18, 32); whether levels of bioactive IL-7 in stromal cell supernatants are also reduced in the presence of DHT is under active investigation. Other mechanisms through which TGF- $\beta$ may affect B cell development include acceleration of apoptosis and inhibition of cellular proliferation $(33,36)$, two cellular processes that are associated with actions of DHT in the thymus $(37,38)$. The many similar effects of TGF- $\beta$ and androgens on developing B cells support a functional link, although the molecular mechanisms by which androgens increase TGF- $\beta$ expression have not been elucidated to date.

Estrogens and androgens both have downregulatory effects on B cell development, yet they show different effects on expression of autoimmunity, with estrogens generally promoting immune reactivity. This apparent paradox may be explained by the fact that receptors for estrogen but not androgen are expressed in peripheral immune cells (39). Estrogen mediates increased antibody and autoantibody production (40) and prevents induction of tolerance (41) in mature B cells. Acceleration of autoreactivity is most likely related to these peripheral effects of estrogens.

The mechanisms responsible for the ameliorating effects of androgens on autoimmune disease remain poorly understood. Findings in the current study suggest two possible pathways. One is in the generation of new $B$ cells, a process that is reduced by androgens, and that can lead to decreased production of autoantibodies in a host that is for other reasons susceptible to autoimmunity, as has been demonstrated in autoimmune-prone mouse strains (42). These effects also can be exerted in humans, as demonstrated by the ability of androgen replacement to reduce autoantibody levels in hypogonadal men with lupus (43). A second, potentially related mechanism is through production of downregulatory mediators such as TGF- $\beta$. The importance of this mediator in autoimmunity is illustrated by effects in murine experimental autoimmune encephalomyelitis (EAE), which is a model for the human disease multiple sclerosis. Induction of protective tolerance in males with EAE is associated with increased production of TGF- $\beta$, a process that takes place in intact but not castrated males, suggesting that the cytokine response is hormone-dependent (44). Further identification of the mediators and signaling pathways that are involved in the effects of androgens on B cell development may elucidate underlying mechanisms and suggest novel therapeutic approaches to autoimmune diseases.

\section{Acknowledgments}

This work was supported by grants from the NIH (DK41053 and AI-41575, to N.J. Olsen), the Nashville Chapter of the Lupus Foundation of America (to W.J. Kovacs), and the Department of Veterans Affairs (to W.J. Kovacs). The expert technical assistance of Yuxin Dong, Jin Fan, Nicola Green, Roger Jackson, Xuan Li, Wendell Nicholson, Andrew Strang, Adam Swallows, and Maxine Tur- ney is appreciated. David MacFarland of the Vanderbilt Flow Cyotmetry Laboratory assisted with flow cytometric analyses. Special thanks to Geraldine Miller and Eugene Oltz for critical reading of the manuscript.

1. Erben, R.G., Raith, S., Eberle, J., and Stangassinger, M. 1998. Ovariectomy augments B lymphopoiesis and generation of monocytemacrophage precursors in rat bone marrow. Am. J. Physiol. 274:E476-E483.

2. Miyaura, C., et al. 1997. Increased B-lymphopoiesis by interleukin 7 induces bone loss in mice with intact ovarian function: similarity to estrogen deficiency. Proc. Natl. Acad. Sci. USA. 94:9360-9365.

3. Masuzawa, T., et al. 1994. Estrogen deficiency stimulates B lymphopoiesis in mouse bone marrow. J. Clin. Invest. 94:1090-1097.

4. Medina, K.L., and Kincade, P.W. 1994. Pregnancy-related steroids are potential negative regulators of B lymphopoiesis. Proc. Natl. Acad. Sci. USA. 91:5382-5386.

5. Medina, K.L., Strasser, A., and Kincade, P.W. 2000. Estrogen influences the differentiation, proliferation, and survival of early B-lineage precursors. Blood. 95:2059-2067.

6. Smithson, G., Medina, K., Ponting, I., and Kincade, P.W. 1995. Estrogen suppresses stromal cell-dependent lymphopoiesis in culture. J. Immunol. 155:3409-3417.

7. Smithson, G., Couse, J.F., Lubahn, D.B., Korach, K.S., and Kincade, P.W. 1998. The role of estrogen receptors and androgen receptors in sex steroid regulation of B lymphopoiesis. J. Immunol. 161:27-34.

8. Thurmond, T.S., et al. 2000. Role of estrogen receptor alpha in hematopoietic stem cell development and B lymphocyte maturation in the male mouse. Endocrinology. 141:2309-2318.

9. Viselli, S.M., Stanziale, S., Shults, K., Kovacs, W.J., and Olsen, N.J. 1995. Castration alters peripheral immune function in normal male mice. Immunology. 84:337-342.

10. Wilson, C.A., Mrose, S.A., and Thomas, D.W. 1995. Enhanced production of B lymphocytes after castration. Blood. 85:1535-1539.

11. Ellis, T.M., Moser, M.T., Le, P.T., Flanigan, R.C., and Kwon, E.D. 2001. Alterations in peripheral B cells and B cell progenitors following androgen ablation in mice. Int. Immunol. 13:553-558.

12. Viselli, S.M., Reese, K.R., Fan, J., Kovacs, W.J., and Olsen, N.J. 1997. Androgens alter B cell development in normal male mice. Cell Immunol. 182:99-104.

13. Olsen, N.J., Watson, M.B., and Kovacs, W.J. 1991. Studies of immunological function in mice with defective androgen action. Distinction between alterations in immune function due to hormonal insensitivity and alterations due to other genetic factors. Immunology. 73:52-57.

14. Olsen, N.J., Watson, M.B., Henderson, G.S., and Kovacs, W.J. 1991. Androgen deprivation induces phenotypic and functional changes in the thymus of adult male mice. Endocrinology. 129:2471-2476.

15. Burroughs, J., Gupta, P., Blazar, B.R., and Verfaillie, C.M. 1994. Diffusible factors from the murine cell line M2-10B4 support human in vitro hematopoiesis. Exp. Hematol. 22:1095-1101.

16. Kincade, P.W., Paige, C.J., Parkhouse, R.M., and Lee, G. 1978. Characterization of murine colony-forming B cells. I. Distribution, resistance to anti-immunoglobulin antibodies, and expression of Ia antigens. $J$. Immunol. 120:1289-1294.

17. Shimozato, T., and Kincade, P.W. 1997. Indirect suppression of IL-7responsive B cell precursors by vasoactive intestinal peptide. J. Immunol. 158:5178-5184.

18. Lee, G., Namen, A.E., Gillis, S., Ellingsworth, L.R., and Kincade, P.W. 1989. Normal B cell precursors responsive to recombinant murine IL7 and inhibition of IL-7 activity by transforming growth factor-beta. $J$. Immunol. 142:3875-3883.

19. Lemoine, F.M., Krystal, G., Humphries, R.K., and Eaves, C.J. 1988. Autocrine production of pre-B-cell stimulating activity by a variety of transformed murine pre-B-cell lines. Cancer Res. 48:6438-6443.

20. Olsen, N.J., Zhou, P., Ong, H., and Kovacs, W.J. 1993. Testosterone induces expression of transforming growth factor-beta 1 in the murine thymus. J. Steroid Biochem. Mol. Biol. 45:327-332.

21. Singh, S.M., Gauthier, S., and Labrie, F. 2000. Androgen receptor antagonists (antiandrogens): structure-activity relationships. Curr. Med. Chem. 7:211-247.

22. Olsen, N.J., Olson, G., Viselli, S.M., Gu, X., and Kovacs, W.J. 2001. Androgen receptors in thymic epithelium modulate thymus size and thymocyte development. Endocrinology. 142:1278-1283.

23. Garvy, B.A., King, L.E., Telford, W.G., Morford, L.A., and Fraker, P.J. 1993. Chronic elevation of plasma corticosterone causes reductions in the number of cycling cells of the B lineage in murine bone marrow and induces apoptosis. Immunology. 80:587-592.

24. Tarlinton, D. 1994. B-cell differentiation in the bone marrow and the periphery. Immunol. Rev. 137:203-229.

25. Murphy, W.J., Durum, S.K., Anver, M.R., and Longo, D.L. 1992. 
Immunologic and hematologic effects of neuroendocrine hormones. Studies on DW/J dwarf mice. J. Immunol. 148:3799-3805.

26. Foster, M., Montecino-Rodriguez, E., Clark, R., and Dorshkind, K. 1998. Regulation of $\mathrm{B}$ and $\mathrm{T}$ cell development by anterior pituitary hormones. Cell. Mol. Life Sci. 54:1076-1082.

27. Montecino-Rodriguez, E., Clark, R., Johnson, A., Collins, L., and Dorshkind, K. 1996. Defective B cell development in Snell dwarf (dw/dw) mice can be corrected by thyroxine treatment. J. Immunol. 157:3334-3340.

28. Jardieu, P., Clark, R., Mortensen, D., and Dorshkind, K. 1994. In vivo administration of insulin-like growth factor-I stimulates primary $B$ lymphopoiesis and enhances lymphocyte recovery after bone marrow transplantation. J. Immunol. 152:4320-4327.

29. Takeda, H., Chodak, G., Mutchnik, S., Nakamoto, T., and Chang, C. 1990. Immunohistochemical localization of androgen receptors with mono- and polyclonal antibodies to androgen receptor. J. Endocrinol. 126:17-25.

30. Kumar, N., Shan, L.X., Hardy, M.P., Bardin, C.W., and Sundaram, K. 1995. Mechanism of androgen-induced thymolysis in rats. Endocrinology. 136:4887-4893.

31. Danel, L., et al. 1985. Distribution of androgen and estrogen receptors among lymphoid and haemopoietic cell lines. Leuk. Res. 9:1373-1378.

32. Tang, J., et al. 1997. TGF-beta down-regulates stromal IL-7 secretion and inhibits proliferation of human B cell precursors. J. Immunol. 159:117-125.

33. Lee, G., Ellingsworth, L.R., Gillis, S., Wall, R., and Kincade, P.W. 1987. Beta transforming growth factors are potential regulators of B lymphopoiesis. J. Exp. Med. 166:1290-1299.

34. Robledo, M.M., et al. 1996. Characterization of TGF-beta 1-binding proteins in human bone marrow stromal cells. Br. J. Haematol. 93:507-514.
35. Keller, J.R., et al. 1990. Transforming growth factor beta directly regulates primitive murine hematopoietic cell proliferation. Blood. 75:596-602.

36. Lebman, D.A., and Edmiston, J.S. 1999. The role of TGF-beta in growth, differentiation, and maturation of B lymphocytes. Microbes Infect. 1:1297-1304.

37. Olsen, N.J., Viselli, S.M., Fan, J., and Kovacs, W.J. 1998. Androgens accelerate thymocyte apoptosis. Endocrinology. 139:748-752.

38. Olsen, N.J., Viselli, S.M., Shults, K., Stelzer, G., and Kovacs, W.J. 1994. Induction of immature thymocyte proliferation after castration of normal male mice. Endocrinology. 134:107-113.

39. Olsen, N.J., and Kovacs, W.J. 1996. Gonadal steroids and immunity. Endocr. Rev. 17:369-384.

40. Verthelyi, D.I., and Ahmed, S.A. 1998. Estrogen increases the number of plasma cells and enhances their autoantibody production in nonautoimmune C57BL/6 mice. Cell. Immunol. 189:125-134.

41. Bynoe, M.S., Grimaldi, C.M., and Diamond, B. 2000. Estrogen up-regulates Bcl-2 and blocks tolerance induction of naive B cells. Proc. Natl. Acad. Sci. USA. 97:2703-2708.

42. Morton, J.I., Weyant, D.A., Siegel, B.V., and Golding, B. 1981. Androgen sensitivity and autoimmune disease. I. Influence of sex and testosterone on the humoral immune response of autoimmune and non-autoimmune mouse strains to sheep erythrocytes. Immunology. 44:661-669.

43. Olsen, N.J., and Kovacs, W.J. 1995. Case report: testosterone treatment of systemic lupus erythematosus in a patient with Klinefelter's syndrome. Am. J. Med. Sci. 310:158-160.

44. Bebo, B.F., Jr., et al. 1999. Gender differences in protection from EAE induced by oral tolerance with a peptide analogue of MBP-Ac1-11. J. Neurosci. Res. 55:432-440. 